\title{
Níveis de Metionina + Cistina para Pintos de Corte Mantidos em Ambiente Termoneutro ${ }^{1}$
}

\author{
Adhemar Rodrigues de Oliveira Neto ${ }^{2}$, Rita Flávia Miranda de Oliveira ${ }^{3}$, Juarez Lopes \\ Donzele $^{3}$, Paulo Roberto Cecon ${ }^{3}$, Roberta Gomes Marçal Vieira Vaz ${ }^{4}$, Eliane Gasparino ${ }^{5}$
}

RESUMO - O experimento foi realizado para determinação da exigência de metionina + cistina (met + cis) da ração para pintos de corte do $1^{\mathrm{o}}$ ao $21^{\underline{o}}$ dia de idade mantidos em ambiente termoneutro. Foram utilizados 400 pintos de corte machos Avian Farms, distribuídos em delineamento inteiramente casualizado, com cinco tratamentos $(0,756 ; 0,810 ; 0,866 ; 0,920$ e $0,976 \%$ de met + cis $)$, oito repetições e dez aves por unidade experimental. O aumento do nível de met + cis influenciou o ganho de peso (GP), a conversão alimentar, o consumo de met + cis, a deposição de proteína, o peso absoluto do fígado, da moela, dos pulmões e o peso relativo dos pulmões. Não foi verificado efeito dos níveis de met + cis sobre o consumo de ração, a deposição de gordura, o peso absoluto da carcaça, do coração, do proventrículo e do intestino, nem sobre o peso relativo do coração, do fígado, da moela, do proventrículo e do intestino. O nível de $0,866 \%$ de met + cis total $(0,790 \%$ de met + cis digestível calculado), correspondente à relação met + cis/ lis total de $69 \%$ (72\% para digestível), proporcionou o melhor GP, enquanto o nível de $0,898 \%$ de met + cis total ( $0,822 \%$ digestível calculado), correspondente à relação met + cis/lis total de $72 \%$ (74\% para digestível), proporcionou melhor valor de conversão alimentar de pintos de corte mantidos em ambiente termoneutro.

Palavras-chave: ambiente térmico, aminoácidos sulfurosos, exigência nutricional, desempenho

\section{Levels of Methionine + Cystine for Broiler Chicks on Thermoneutral Environment}

\begin{abstract}
The experiment was conducted to determine the effect of dietary methionine + cystine (met + cys) requirement of 1-to-21-day-old broiler chicks on thermoneutral environment. Four hundred Avian Farm male broiler chicks were assigned to a randomized experimental design with five treatments $(0.756,0.810,0.866,0.920$, and $0.976 \%$ of met + cys $)$, eight replicates of ten birds. Weight gain (WG), feed:gain ratio, met + cys intake, protein deposition of absolute weights of liver, gizzard, and lung and relative weights of lung were affected by the increasing dietary met + cys levels. No effect of met + cys levels on feed intake, fat deposition, absolute weights of carcass, proventriculus, heart, and intestine or relative weights of heart, liver, gizzard, proventriculus, lung and intestines was verified. The best WG was observed at $0.866 \%$ met + total cys $(0.790 \%$ met + digestible cys calculated $)$ level, corresponding to $69 \%$ met + cys/total lys ratio $(72 \%$ for digestible) and the best feed:gain ratio value was observed at $0.894 \%$ met + total cys $(0.822 \%$ digestible calculated $)$ level, corresponding to $72 \%$ met + cys/ digestible lys total ratio $(74 \%$ met + cys $/$ digestible lys ratio), for broiler chicks on thermoneutral environment.
\end{abstract}

Key Words: nutritional requirement, performance, sulphurous amino acids, thermal environment

\section{Introdução}

A formulação e o balanceamento de rações consistem na mistura de vários alimentos, com a finalidade de atender às exigências nutricionais das aves para que possam expressar todo o seu potencial genético. Nos últimos anos, tem-se discutido a utilização adequada de nutrientes pelas aves na fase inicial, em razão da necessidade de se produzir rações contendo matérias-primas de melhor digestibilidade. Além do conhecimento sobre os alimentos, é necessário conhecer a exigência nutricional de pintos de corte em suas diferentes fases de vida.

Entre os principais nutrientes exigidos pelas aves, encontra-se a proteína bruta, constituída principalmente por aminoácidos totais, entre os quais a metionina é o primeiro limitante em rações práticas à base de milho e farelo de soja, para pintos de corte.

Desta forma, a DL-metionina é incorporada de forma rotineira em rações para aves na avicultura industrial, uma vez que a metionina pode ser convertida em cistina, aumentando os níveis de ambos os

\footnotetext{
${ }^{1}$ Parte da Tese de Doutorado do primeiro autor. Projeto financiado pela FAPEMIG.

2 Nutricionista - Nutrição DSM Produtos Nutricionais do Brasil Ltda. E.mail: adhemar.oliveira@dsm.com

3 Professor do DZO/UFV. E.mail: flavia@mail.ufv.br; donzele@mail.ufv.br

4 Estudante de Doutorado do DZO/UFV. E.mail: robertavaz@lycos.com

5 Professor do DZO/UEM.
} 
aminoácidos nas rações até os valores recomendados na literatura e/ou nos manuais das linhagens comerciais. Todavia, a exigência de metionina + cistina (met + cis) sugerida pelas tabelas existentes varia, sendo recomendados desde 0,80\% (Mitchell \& Robbins, 1984), 0,86\% (Rostagno, 1990) até $0,90 \%$ de met + cis total (NRC, 1994).

Essas divergências encontradas na literatura podem ser explicadas pelas diferenças de linhagens, sexo, temperatura ambiente, níveis de proteína bruta e concentração de energia metabolizável da ração verificadas nesses trabalhos.

Quanto à temperatura ambiente, existem evidências que sugerem alterações na exigência de aminoácidos para pintos de corte quando mantidos em diferentes temperaturas, o que pode ser decorrente de modificações hormonais e fisiológicas quando as aves são expostas a estresse térmico. Essas alterações no metabolismo dos animais podem causar mudanças no peso de órgãos e no empenamento (Oliveira Neto, 1999), no rendimento de cortes nobres e no perfil de aminoácidos no plasma sanguíneo (Geraert et al., 1996) e, como conseqüência, podem ocorrer mudanças na exigência dos nutrientes (aminoácidos) utilizados no processo de síntese protéica destes tecidos corporais.

Este estudo foi realizado para se determinar a exigência de aminoácidos sulfurados (metionina + cistina) para pintos de corte de 1 a 21 dias de idade mantidos em ambiente termoneutro.

\section{Material e Métodos}

O experimento foi conduzido nas câmaras climatizadas no Laboratório de Bioclimatologia Animal do Departamento de Zootecnia da Universidade Federal de Viçosa, em Viçosa, MG.

Foram utilizados 400 pintos de corte machos da linhagem Avian Farms, no período de 1 a 21 dias de idade, com peso inicial de 47,8 $\pm 0,69 \mathrm{~g}$, vacinados contra as doenças de Marek e de Bouba Aviária. O delineamento experimental utilizado foi o inteiramente casualizado, com cinco tratamentos (níveis de metionina + cistina), oito repetições e 10 aves por unidade experimental.

As aves foram alojadas em compartimentos de baterias metálicas, com piso telado de área igual a $0,72 \mathrm{~m}^{2}$, dotados de comedouros e de bebedouros tipo calha, constituindo-se cada compartimento uma unidade experimental.
O programa de luz adotado durante todo o período experimental foi o contínuo, com 24 horas de luz artificial, utilizando-se duas lâmpadas fluorescentes de 75 watts cada.

Para a manutenção do conforto térmico das aves durante o período experimental, foram atendidas as recomendações do manual da Avian Farms (1998) quanto à combinação da temperatura ambiente e da umidade relativa.

O monitoramento da temperatura e da umidade foi feito por meio de termômetros (de máxima e mínima, de bulbo seco e de bulbo úmido e de globo negro) colocados a uma altura intermediária em relação ao compartimento central da bateria. As leituras dos termômetros foram realizadas diariamente, durante todo o período experimental, três vezes ao dia $(8,13$ e $18 \mathrm{~h})$.

$\mathrm{Na}$ Tabela 1 são apresentados os valores médios de temperatura e umidade relativa do ar no interior da câmara climática, verificados durante o período experimental, e do índice de temperatura de globo e umidade (ITGU), calculados segundo Buffington et al. (1981).

Para a formulação das rações experimentais, foi considerada uma ração basal (Tabela 2), deficiente em met + cis $(0,756 \%)$, à base de milho e farelo de soja, suplementada com quatro níveis de DL-metionina (99\%) em substituição ao amido de milho, resultando em rações com 0,$810 ; 0,866 ; 0,920$ e $0,976 \%$ de met + cis total, isoprotéicas e isocalóricas em relação à ração basal. As exigências nutricionais mínimas aten-

Tabela 1 - Temperatura do ar, umidade relativa e do índice de temperatura de globo e umidade (ITGU) observados nas câmaras climáticas

Table 1 - Air temperature, relative humidity and black globe humidity index (BGHI) average conditions observed in the climatic chambers

\begin{tabular}{lccc}
\hline $\begin{array}{l}\text { Idade (dias) } \\
\text { Age (days) }\end{array}$ & $\begin{array}{c}\text { Temperatura } \\
\text { do ar }\left({ }^{\circ} \mathrm{C}\right) \\
\text { Air temperature } \\
\left({ }^{\circ} \mathrm{C}\right)\end{array}$ & $\begin{array}{c}\text { Umidade } \\
\text { relativa }(\%) \\
\text { Relative humidity } \\
(\%)\end{array}$ & ITGU \\
\hline 1 & $33,0 \pm 0,0$ & $58 \pm 0,2$ & $83 \pm 0,1$ \\
2 & $32,1 \pm 0,1$ & $58 \pm 0,9$ & $81 \pm 0,1$ \\
3 & $31,0 \pm 0,0$ & $56 \pm 0,5$ & $80 \pm 0,1$ \\
4 & $30,1 \pm 0,0$ & $56 \pm 0,2$ & $78 \pm 0,1$ \\
5 & $30,0 \pm 0,0$ & $56 \pm 1,7$ & $79 \pm 0,2$ \\
6 & $29,3 \pm 0,0$ & $61 \pm 2,0$ & $78 \pm 0,3$ \\
$7-12$ & $28,7 \pm 0,4$ & $60 \pm 3,0$ & $77 \pm 0,6$ \\
$13-17$ & $27,1 \pm 0,4$ & $63 \pm 2,4$ & $75 \pm 0,4$ \\
$18-21$ & $25,8 \pm 0,3$ & $66 \pm 3,6$ & $74 \pm 0,4$ \\
\hline
\end{tabular}


Tabela 2 - Composições centesimal e calculada da ração basal

Table 2 - Ingredient and calculated compositions (\%) of basal diet

Ingrediente

$(\%)$

Ingredient

Milho $(\text { Corn - } 8.72 \% \mathrm{CP})^{1}$

Farelo de soja (Soybean meal $-46.72 \% C P)^{1}$

Amido (Starch)

Óleo vegetal (Vegetable oil)

36,900

Fosfato bicálcico (Dicalcium phosphate)

Calcário (Limestone)

Sal (Salt)

Mistura mineral ${ }^{2}$ (Mineral mix)

Mistura vitamínica ${ }^{3}$ (Vitamin mix)

56,500

0,343

2,330

1,816

1,125

0,390

0,050

DL-metionina (99\%) (DL-methionine)

0,100

L-treonina (L-threonine)

0,192

0,005

L-triptofano (L-tryptophan)

0,009

Cloreto de colina (60\%) (Choline cloride)

0,125

Anticoccidiano 4 (Anticoccidian)

0,050

Bacitracina de zinco (Zinc bacitracin)

0,055

BHT

0,010

TOTAL

100,000

Composição calculada

Calculated composition

Proteína bruta (Crude protein) (\%)

22,12

Energia metabolizável (Metabolizable energy) (kcal/kg)

3.000

Sódio (Sodium) (\%)

Cálcio (Calcium) $(\%)$

0,200

0,995

Fósforo disponível (Available phosphorous) (\%)

0,453

Met + cis total (Total Met + cys) $(\%)$

0,756

Met + cis digestível (Digestible Met + cys) $(\%)$

0,682

Lisina total (Total lysine) (\%)

1,248

Lisina digestível (Digestible lysine) (\%)

1,100

Treonina digestível (Digestible threonine) (\%)

0,737

Triptofano digestível (Digestible tryptophan) (\%)

0,176

${ }^{1}$ Valor obtido no laboratório de Nutrição Animal do DZO/UFV, de acordo com metodologia descrita por Silva (1990).

1 Value obtained in the Laboratory of Animal Nutrition of DZO/UFV, according to Silva (1990).

2 Quantidade/kg do produto (content/kg of product): Fe - 100 mg; Co- 2,0 mg; Cu - 20,0 mg; Mg - 160,0 mg; Zn - 100,0 mg; I - 2,0 mg; q.s.p. $-1.000 \mathrm{~g}$.

${ }^{3}$ Quantidade/kg do produto (content/kg of product): Vit. A - 10.000 U.I.; Vit. D $3-2.000$ U.I.; Vit. E - 30 U.I.; Vit. B 1 - 2,0 mg; Vit. B $-6,0$ mg; Vit. $\mathrm{B}_{6}-4,0 \mathrm{mg}$; Vit. $\mathrm{B}_{12}-$ 0,015 mg; Ác. pantotênico (Panthotenic acid) - 12,0 mg; Biotina (Biotine) - 0,1 mg; Vit. K 3 - 3,0 mg; Ác. fólico (Folic acid) - 1,0 mg; Ác. nicotínico (Nicotinic acid) - 50,0 mg; Se - 0,25 mg; q.s.p. - $1.000 \mathrm{~g}$.

4 Coxixtac $12 \%$ - Salinomicina (Coxixtac $12 \%$ - Salinomicine).

deram às recomendações de Rostagno et al. (2000), com exceção do nível de met + cis digestível.

Os níveis de met + cis totais avaliados neste estudo corresponderam aos níveis de met + cis digestíveis de 0,$682 ; 0,736 ; 0,790 ; 0,844$ e $0,898 \%$ e às relações met + cis digestível/lisina digestível, respectivamente, de $62,67,72,77$ e $82 \%$.

As variáveis estudadas foram: consumo de ração, ganho de peso, conversão alimentar, consumo de met + cist, deposição de gordura e de proteína na carcaça e pesos relativo e absoluto dos órgãos comestíveis (coração, fígado e moela) e não-comestíveis (proventrículo, pulmão e intestino).

O fornecimento de ração e água (trocada duas vezes ao dia) foi ad libitum. O consumo de ração foi calculado pela diferença entre a quantidade de ração fornecida, os desperdícios e as sobras das rações experimentais, pesadas no início e no final da fase experimental. Para determinação do ganho de peso, as aves foram pesadas no início e no final do experimento. A partir dos dados de consumo de ração e de ganho de peso, calculou-se a conversão alimentar dos animais.

Ao final do experimento, após jejum de seis horas, as aves foram pesadas. Quatro aves de cada repetição, considerando-se o peso médio de cada unidade experimental ( $10 \%$ acima e abaixo da média), foram escolhidas e abatidas por meio de deslocamento cervical. Após serem sangradas, depenadas e evisceradas, as aves foram pesadas. 
As carcaças inteiras (incluindo pés e cabeça), sem vísceras e sangue, foram moídas, durante 15 minutos, em "cutter" comercial de $30 \mathrm{HP}$ e $1.775 \mathrm{rpm}$, obtendo-se amostra, para posterior determinação da deposição de gordura e de proteína na carcaça.

As amostras de carcaça foram inicialmente présecas em estufa com ventilação forçada a $\pm 60^{\circ} \mathrm{C}$, durante 72 horas. Posteriormente, em razão do alto teor de gordura, foi realizado pré-desengorduramento pelo método a quente, em aparelho extrator do tipo "Soxhlet", durante quatro horas. Em seguida, as amostras foram moídas e acondicionadas em vidros, que foram armazenados para posteriores análises.

Os teores de água e de gordura extraídos no processo de preparo das amostras foram considerados para a correção dos valores das análises. As análises de extrato etéreo e de proteína bruta das amostras foram realizadas no Laboratório de Nutrição Animal do Departamento de Zootecnia da UFV, conforme metodologia descrita por Silva (1990).

Um grupo adicional de 15 aves com um dia de idade foi abatido, para determinação da composição corporal das aves no início do experimento. As deposições de gordura e de proteína na carcaça foram calculadas pela diferença entre a composição da carcaça dos pintos de corte com 21 dias e com 1 dia de idade.

Os órgãos foram cortados longitudinalmente, pendurados à sombra, para que o sangue escorresse, e pesados em seguida. O intestino foi aberto em toda sua extensão, retirando-se o seu conteúdo, que foi lavado e, após escorrido o excesso de água, foi pesado. O peso relativo (\%) dos órgãos foi calculado em relação ao peso da carcaça eviscerada.

As análises estatísticas das variáveis de desempenho (ganho de peso, conversão alimentar e consumo de met + cis), de deposição de gordura e de proteína na carcaça e de peso dos órgãos foram realizadas utilizandose o programa SAEG (Sistema para Análise Estatística e Genética), desenvolvido pela Universidade Federal de Viçosa (1997). A estimativa de exigência de met + cis foi estabelecida por meio de modelos de regressão polinomial e do modelo descontínuo - LRP (Linear Response Plateau), conforme o melhor ajuste dos dados.

\section{Resultados e Discussão}

Os resultados de desempenho, de consumo de metionina + cistina $($ met + cis) e das deposições de proteína e de gordura na carcaça dos pintos de corte no período de 1 a 21 dias de idade, mantidos em ambiente termoneutro, são apresentados na Tabela 3 .

Não se observou efeito $(\mathrm{P}>0,05)$ dos níveis de aminoácidos sulfurosos sobre o peso final das aves. Entretanto, constatou-se que, nos dois menores níveis de met + cis avaliados, o peso final dos pintos foi significativamente menor $(3,2 \%)$, em valor absoluto, que a média dos demais tratamentos.

Verificou-se efeito $(\mathrm{P}<0,03)$ dos níveis de met + cis da ração sobre o ganho de peso (GP), que aumentou de forma linear (Tabela 5). Embora tenha aumentado de forma linear, constatou-se que, a partir do nível de $0,866 \%$ de met + cis, não houve melhoria no valor absoluto do GP, indicando que, a partir desse nível, a exigência de met + cis das aves para GP foi atendida. O valor de $0,866 \%$ de met + cis total corresponde ao valor de met + cis digestível calculado de $0,790 \%$, estabelecendo uma relação entre a met + cis digestível/lis digestível de $72 \%$. O resultado encontrado para a melhor relação entre os aminoácidos met + cis digestível/lis digestível, neste estudo, assemelha-se àqueles de 71 e $72 \%$ recomendados, respectivamente, por Rostagno et al. (2000) e Baker \& Han (1994) para pintos de corte no período de 1 a 21 dias de idade.

Estudando a exigência de met + cis em dois níveis de proteína bruta (20 e 23\%) em pintos de corte, Silva (1996) também encontrou efeito linear dos níveis de PB e de met + cis das rações sobre o ganho de peso das aves. Da mesma forma, Silva (1997) observou maior GP à medida que os níveis de met + cis foram aumentados, verificando que os dados se ajustavam melhor no modelo estatístico "Linear Response Plateau" - LRP.

Por outro lado, Albino et al. (1999) encontraram resposta quadrática dos níveis de met + cis sobre o GP de pintos de corte, sendo os níveis de 0,898 e $0,906 \%$ de met + cis os que proporcionaram o maior ganho de peso em machos das linhagens Hubbard e Ross, respectivamente.

A variação observada no GP das aves ocorreu de forma independente do consumo de ração (CR), que não se alterou $(\mathrm{P}>0,05)$ em função dos níveis de met + cis avaliados. Este resultado contrasta com o relato de Schutte \& Pack (1995), que afirmaram que as aves possuem a capacidade de compensar o consumo marginal de metionina, aumentando o consumo de ração para atender sua exigência, indicando que a metionina pode regular o consumo em pintos de corte. 
Tabela 3 - Efeito do nível de met + cis da ração sobre o desempenho e a deposições de proteína e gordura na carcaça de pintos de corte mantidos em ambiente termoneutro

Table 3 - Effect of dietary met + cys level on performance and protein and fat deposition in the carcass of male broilers on thermoneutral environment

\begin{tabular}{|c|c|c|c|c|c|c|}
\hline \multirow[t]{2}{*}{$\begin{array}{l}\text { Parâmetro } \\
\text { Parameter }\end{array}$} & \multicolumn{5}{|c|}{$\begin{array}{l}\text { Nível de met }+ \text { cis }(\%) \\
\text { Met and cys level }\end{array}$} & \multirow[t]{2}{*}{$\mathrm{CV}(\%)$} \\
\hline & 0,756 & 0,810 & 0,866 & 0,920 & 0,976 & \\
\hline Peso final (g) (Final weight, g) & 780 & 784 & 815 & 798 & 810 & 3,57 \\
\hline Ganho de peso $(\mathrm{g})^{1}$ (Weight gain, $g$ ) & 732 & 736 & 767 & 750 & 762 & 3,78 \\
\hline Consumo de ração $(\mathrm{g})$ (Feed intake, $g$ ) & 1028 & 1017 & 1038 & 1016 & 1046 & 3,52 \\
\hline Conversão alimentar ${ }^{2}$ (Feed: gain ratio) & 1,40 & 1,38 & 1,35 & 1,35 & 1,37 & 1,96 \\
\hline Consumo met $+\operatorname{cis}^{3}(\mathrm{~g})($ Met + cys intake, $g)$ & 7,8 & 8,0 & 9,0 & 9,3 & 10,2 & 3,62 \\
\hline Deposição de gordura (g) (Fat deposition, g) & 59 & 56 & 62 & 61 & 61 & 6,29 \\
\hline Deposição de proteína $^{2}(\mathrm{~g})$ (Protein deposition, g) & 93 & 92 & 96 & 100 & 94 & 5,00 \\
\hline
\end{tabular}

1,3 Efeito linear $(P<0,03$ e $P<0,01$, respectivamente).

1,3 Linear effect $(P<0.03$ and $P<0.01$, respectively).

2 Efeito quadrático $(P<0,02)$.

2 Quadratic effect $(P<0.02)$.

Entretanto, esse efeito da metionina sobre a regulação do consumo de ração não foi observado neste estudo.

Como o $\mathrm{CR}$ não variou entre os tratamentos $(\mathrm{P}>0,05)$, o consumo de met + cis elevou $(\mathrm{P}<0,01)$ de forma linear de acordo com o nível de aminoácidos sulfurados da ração (Tabela 5). Aumento no consumo de met + cis para pintos de corte na fase de 1 a 21 dias, em função de seus níveis nas rações, também foi verificado por Schutte \& Pack (1995) e Silva (1996).

Os níveis de met + cis da ração influenciaram $(\mathrm{P}<0,01)$ de forma quadrática a conversão alimentar (CA) das aves, que melhorou até o nível estimado de $0,898 \%$ de met + cis (Figura 1), correspondente ao nível digestível calculado de $0,822 \%$. Esse resultado foi semelhante aos obtidos por Albino et al. (1995, 1999), que também observaram resposta positiva dos níveis de met + cis da ração sobre a CA.

A melhor resposta das aves ocorreu quando a relação met + cis digestível/lis digestível correspondeu a $75 \%$. Esse valor ficou acima dos 72 e $71 \%$ propostos, respectivamente, por Baker e Han (1994) e Rostagno et al. (2000) como a relação ideal na proteína das rações formuladas para pintos de corte na fase de 1 a 21 dias de idade.

Não foi observado efeito $(\mathrm{P}>0,05)$ dos tratamentos sobre a deposição de gordura. No entanto, a deposição de proteína (DPC) na carcaça das aves aumentou $(\mathrm{P}<0,01)$ de forma quadrática até o nível estimado de $0,894 \%$ de met + cis (Figura 2 ), correspondente ao nível calculado de $0,818 \%$ de aminoácidos sulfurados digestíveis e a uma relação met + cis digestível/lis digestível de $74 \%$. Considerando- se que a deposição de proteína, por agregar maior quantidade deágua $(1: 5,26)$ que a de gordura (Kyriazakis et al., 1994), resultando em maior GP e eficiência de ganho, pode-se deduzir que a melhoria no GP e na CA das aves até os níveis de met + cis obtidos neste estudo ocorreu em razão da variação na composição do ganho, que teve a deposição de proteína aumentada.

Evidenciou-se neste estudo que a melhor relação met + cis digestível/lisina digestível na proteína ideal para pintos de corte na fase de 1 a 21 dias varia de acordo com o parâmetro de desempenho. A concentração de met + cis em relação à de lisina na ração foi maior para se obter melhor resposta de CA e DP em relação ao GP.

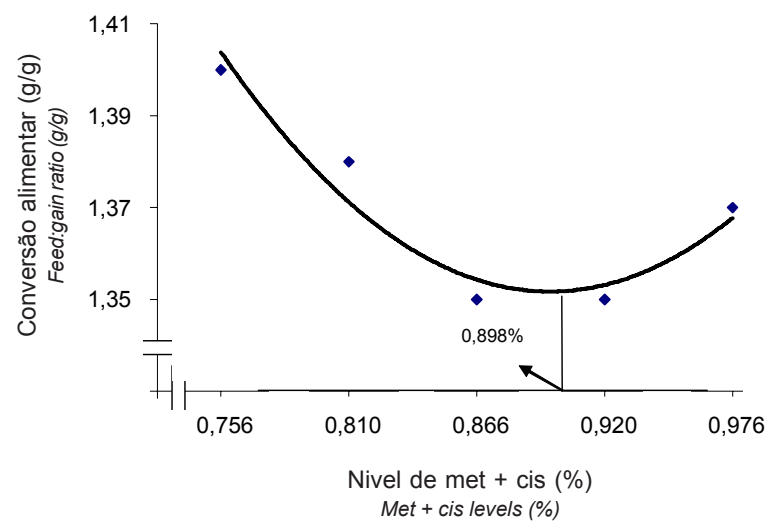

Figura 1 - Conversão alimentar das aves mantidas em ambiente termoneutro no período de 1 a 21 dias de idade, em função do nível de met + cis da ração.

Figure 1 - Feed:gain ratio of birds from 1 to 21 days old on thermoneutral environment, as affected by the dietary met + cys levels. 


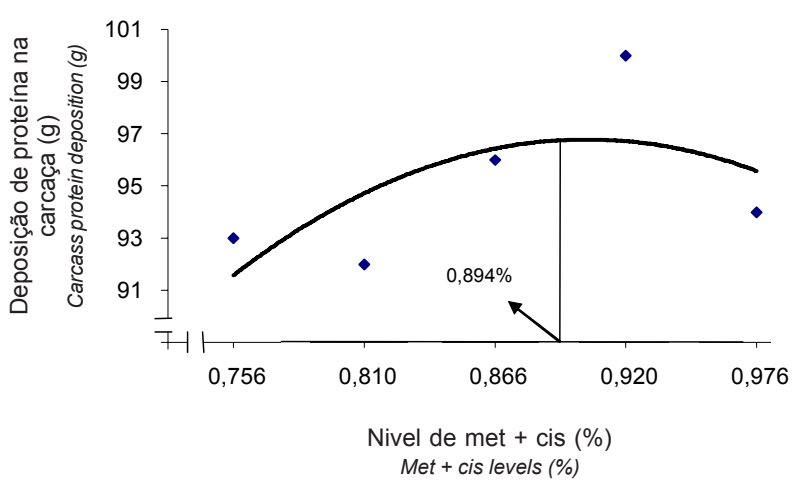

Figura 2 - Deposição de proteína na carcaça das aves mantidas em ambiente termoneutro no período de 1 a 21 dias de idade, em função do nível de met + cis da ração.

Figure 2 - Protein deposition in the carcass of birds on thermoneutral environment, in the period from 1 to 21 days of age, as affected by the dietary met + cys levels.

Os resultados dos pesos absoluto $(\mathrm{g})$ e relativo (\%) das variáveis coração, fígado, moela, proventrículo, pulmão e intestino dos pintos de corte recebendo rações com diferentes níveis de met + cis e mantidos em ambiente termoneutro encontram-se na Tabela 4.

Não se observou variação $(\mathrm{P}>0,10)$ nos pesos absoluto e relativo do coração, proventrículo e do intestino e no peso relativo do fígado e da moela das aves com o aumento da concentração de met + cis das rações. Por outro lado, o peso absoluto do fígado, da moela e do pulmão $(\mathrm{P}<0,02)$ e o peso relativo dos pulmões aumentaram $(\mathrm{P}<0,10)$ de forma linear (Tabela 5) com a elevação dos níveis dos aminoácidos sulfurados na ração.

De acordo com os resultados obtidos para os pesos absoluto (g) e relativo (\%) dos diferentes órgãos, pode-se inferir que as variações encontradas nos pesos destes órgãos ocorreram em função da diferença do desenvolvimento corporal das aves que receberam maiores ou menores níveis de met + cis. O aumento de peso relativo dos pulmões, por sua vez, poderia estar associado ao possível aumento da demanda de oxigênio pelas aves, que tiveram sua massa corporal aumentada com a elevação dos níveis de met + cis das rações.

\section{Conclusões}

Pintos de corte na fase de 1 a 21 dias de idade, mantidos em ambiente termoneutro, exigem $0,866 \%$ de met + cis total, correspondente a $0,790 \%$ de met + cis digestível e a uma relação de $72 \%$ com a lisina digestível, para melhor resposta de ganho de peso, e $0,898 \%$ de met + cis total, correspondente a $0,822 \%$ de met + cis digestível e a uma relação de $74 \%$ com a lisina digestível, para melhores resultados de conversão alimentar.

Tabela 4 - Efeito dos níveis de met + cis da ração sobre os pesos absoluto e relativo de vísceras e órgãos de pintos de corte aos 21 dias de idade mantidos em ambiente termoneutro

Table 4 - Effect of dietary met + cys levels on absolute and relative weights of visceras and organs of male broilers at 21 days of age on thermoneutral environment

\begin{tabular}{|c|c|c|c|c|c|c|}
\hline \multirow[t]{2}{*}{$\begin{array}{l}\text { Parâmetro } \\
\text { Parameter }\end{array}$} & \multicolumn{5}{|c|}{$\begin{array}{l}\text { Nível de met }+ \text { cis }(\%) \\
\text { Met and cys level }\end{array}$} & \multirow[t]{2}{*}{$\mathrm{CV}(\%)$} \\
\hline & 0,756 & 0,810 & 0,866 & 0,920 & 0,976 & \\
\hline \multicolumn{7}{|c|}{ Peso absoluto (g) (Absolute weight, $g$ ) } \\
\hline Carcaça (Carcass) & 578 & 579 & 598 & 603 & 600 & 5,51 \\
\hline Coração (Heart) & 4,6 & 5,3 & 4,6 & 5,4 & 5,0 & 12,01 \\
\hline Fígado $^{1}$ (Liver) & 17 & 17 & 17 & 18 & 19 & 8,19 \\
\hline Moela ${ }^{1}$ (Guizzard) & 15 & 14 & 15 & 15 & 16 & 9,49 \\
\hline Proventrículo (Proventriculus) & 3,7 & 3,8 & 4,2 & 3,8 & 4,2 & 12,87 \\
\hline Pulmão ${ }^{1}$ (Lung) & 3,7 & 3,8 & 4,2 & 4,2 & 4,2 & 14,25 \\
\hline Intestino (Gut) & 26 & 28 & 27 & 29 & 28 & 9,51 \\
\hline \multicolumn{7}{|c|}{ Peso relativo (g) (Relative weight, $g$ ) } \\
\hline Coração (Heart) & 0,81 & 0,92 & 0,79 & 0,89 & 0,83 & 11,61 \\
\hline Fígado (Liver) & 2,99 & 2,99 & 2,94 & 2,97 & 3,10 & 6,85 \\
\hline Moela (Guizzard) & 2,55 & 2,41 & 2,57 & 2,52 & 2,69 & 9,38 \\
\hline Proventrículo (Proventriculus) & 0,64 & 0,66 & 0,71 & 0,63 & 0,70 & 12,99 \\
\hline Pulmão ${ }^{2}$ (Lung) & 0,65 & 0,66 & 0,70 & 0,69 & 0,70 & 12,71 \\
\hline Intestino (Gut) & 4,52 & 4,80 & 4,48 & 4,71 & 4,58 & 8,30 \\
\hline
\end{tabular}

1, 2 Efeito linear $(P<0,02$ e $P<0,10$, respectivamente).

1,2 Linear effect $(P<0.02$ and $P<0.10$, respectively). 
Tabela 5 - Equações de regressão para ganho de peso (GP), conversão alimentar (CA), consumo de met + cis total (CMC), deposição de proteína na carcaça (DPC), pesos absolutos de fígado (FIG), moela (MOE) e pulmão (PUL) e peso relativo do pulmão (RPUL) de aves aos 21 dias de idade mantidas em ambiente termoneutro

Table 5 - Regression equations for weight gain (WG), feed:gain ratio (FG), met + cys intake (MCl), protein deposition in carcass (PDC), absolute weights of liver (LIV), guizzard (GUI), and lung (LUN) and relative weight of lung (RLUN) of birds at 21 days old on thermoneutral environment

\begin{tabular}{|c|c|c|}
\hline $\begin{array}{l}\text { Variável } \\
\text { Variable }\end{array}$ & $\begin{array}{c}\text { Regressão } \\
\text { Regression }\end{array}$ & $* \mathrm{R}^{2}$ ou $\mathrm{r}^{2}$ \\
\hline $\mathrm{GP}(W G)$ & $\hat{\mathrm{Y}}=632,514+135,156 \mathrm{MC} * *$ & 0,60 \\
\hline $\mathrm{CMC}(M C I)$ & $\hat{\mathrm{Y}}=-0,522991+10,8988 \mathrm{MC} 0,218507+9,09341 \mathrm{MC}$ & 0,99 \\
\hline $\mathrm{DPC}(P D C)$ & $\hat{\mathrm{Y}}=-119,538+484,349 \mathrm{MC}-270,875 \mathrm{MC}^{2}$ & 0,44 \\
\hline $\mathrm{FIG}(L I V)$ & $\hat{\mathrm{Y}}=11,9876+6,60001 \mathrm{MC}$ & 0,89 \\
\hline RPUL (RLUN) & $\hat{\mathrm{Y}}=0,482626+0,22959 \mathrm{MC}$ & 0,73 \\
\hline
\end{tabular}

${ }^{*} R^{2}$ - equação quadrática; $r^{2}$ - equação linear $\left(R^{2}\right.$ - quadratic equation; $r^{2}-$ linear equation); ${ }^{* *} \mathrm{MC}-$ metionina + cistina $(M C-$ methionine + cystine $)$

\section{Literatura Citada}

ALBINO, L.F.T.; SILVA, S.H.M.; VARGAS JR., J.G. et al. Níveis de metionina + cistina para pintos de corte de 1 a 21 e 22 a 42 dias de idade. Revista Brasileira de Zootecnia, v.28, p.519-525, 1999 .

ALBINO, L.F.T.; SILVA, S.H.M.; ROSTAGNO, H.S. et al. Níveis de aminoácidos sulfurosos para frangos de corte, no período de 1 a 21 dias. In: CONFERÊNCIA APINCO DE CIÊNCIA E TECNOLOGIA AVÍCOLAS, 1995, Curitiba. Anais... Campinas: FACTA, 1995. p.45-46.

AVIAN FARMS. Broiler manual. In: http://www.avianfarms.com. Avian Farms International Inc., 1998, 34 p.

BAKER, D.H.; HAN, Y. Digestible lysine requirement of male and female broiler chicks during the period three to six weeks posthatching. Poultry Science, v.3, p.739-745, 1994.

BUFFINGTON, D.E.; COLAZZO-AROCHO, A.; CANTON, G.H. et al. Black globe-humidity index (BGHI) as comfort equation for dairy cows. Transaction of the ASAE, v.24, p.711-714, 1981.

GERAERT, P.A.; PADILHA, J.C.F.; GUILLAUMIN, S. Metabolic and endocrine changes induced by chronic heat exposure chickens: biological and endocrinological variables. British Journal of Nutrition, v.75, p.195-204, 1996.

KYRIAZAKIS, I.; DOTAS, D.; EMMANS, G.C. The effects of breed on the relationship between feed composition and the efficiency of protein utilization in pigs. British Journal of Nutrition, v.71, p.849-859, 1994.

MITCHELL, N.S.; ROBBINS, K.R. Effect of dietary energy level on the total sulfur amino acid of growing broilers. Tenesse Farm and Home Science, v.125, p.6-10, 1984.

NATIONAL RESEARCH COUNCIL - NRC. Nutrient requirements of poultry. 9.ed. Washington, D.C.: National Academy of Sciences, 1994. 155p.

OLIVEIRA NETO, A.R. Efeito de níveis de energia da ração e da temperatura ambiente sobre o desempenho e parâmetros fisiológicos de pintos de corte. Viçosa, MG: Universidade Federal de Viçcosa, 1999. 111p. Dissertação (Mestrado em Zootecnia) - Universidade Federal de Viçosa, 1999.
ROSTAGNO, H.S. Valores de composição de alimentos e exigências nutricionais utilizados na formulação de rações para aves. In: REUNIÃO ANUAL DA SOCIEDADE BRASILEIRA DE ZOOTECNIA, 27., 1990, Piracicaba. Anais... Piracicaba: Fundação de Estudos Agrários "Luis de Queiroz", 1990. p.11-30.

ROSTAGNO, H.S.; ALBINO, L.F.T.; DONZELE, J.L. et al. Tabelas brasileiras para aves e suínos - composição de alimentos e exigências nutricionais. 2.ed. Viçosa, MG: Universidade Federal de Viçosa, 2000. 141p.

SILVA, D.J. Análise de alimentos: métodos químicos e biológicos. 2.ed. Viçosa, MG: Universidade Federal de Viçosa, 1990. 165p.

SILVA, M.A. Exigências nutricionais em metionina+cistina para pintos de corte, em função do nível de proteína bruta da ração. Viçosa, MG: Universidade Federal de Viçosa, 1996. 73p. Dissertação (Mestrado em Zootecnia) - Universidade Federal de Viçosa, 1996.

SILVA, S.H.M. Exigências em metionina+cistina para duas marcas comerciais de pintos de corte. Viçosa, MG: Universidade Federal de Viçosa, 1997. 52p. Dissertação (Mestrado em Zootecnia) - Universidade Federal de Viçosa, 1997.

SCHUTTE, J.B.; PACK, M. Sulfur amino acid requirement of broiler chicken from fourteen to thirty-eight days of age. 1. Performance and carcass yield. Poultry Science, v.74, p.480-487, 1995.

UNIVERSIDADE FEDERAL DE VIÇOSA - UFV. SAEG Sistemas de análises estáticas e genéticas. Versão 7.1. Viçosa, MG, 1997. 150p. (Manual do usuário) 